\title{
A cross-sectional relationship between vital capacity and metabolic syndrome and between vital capacity and diabetes in a sample Japanese population
}

\author{
Eiji Oda $\cdot$ Ryu Kawai
}

Received: 24 December 2008/Accepted: 30 June 2009/Published online: 22 July 2009

(C) The Japanese Society for Hygiene 2009

\begin{abstract}
Objectives A lower vital capacity (VC) has been reported to be an independent predictor of diabetes in Western countries. The aim of this study was to examine the relationships between $\mathrm{VC}$ and diabetes and between $\mathrm{VC}$ and metabolic syndrome (MS) in Japanese individuals.

Methods Stepwise multiple linear regressions with fasting glucose as a dependent variable and age, metabolic risk factors, and percentage vital capacity (\%VC) as independent variables were performed using data obtained from 1651 men and 957 women. Area under the receiver operating characteristic curve (AUC) of -\% VC for diagnosing diabetes, MS, and Japanese MS (JMS) were calculated, and stepwise logistic regressions using diabetes, MS, and JMS as dependent variables were performed.

Results Percentage vital capacity was independently associated with fasting glucose in men, but not in women. The AUC of $-\% \mathrm{VC}$ for diagnosing diabetes, MS, and JMS were $0.647,0.606$, and 0.598 , respectively (all $p<0.0001$ ) in men and $0.639(p=0.065), 0.513(p=0.732)$, and $0.668(p=0.01)$, respectively, in women. Age, waist circumference (WC), and \% VC in men and $\mathrm{WC}$ and \% VC in women were independently associated with diabetes. Age and $\% \mathrm{VC}$ in men and only age in women were independently associated with MS, and age and \% VC in both men and women were independently associated with JMS.

Conclusions Among a representative Japanese population, a lower VC was significantly associated with diabetes
\end{abstract}

E. Oda $(\bowtie) \cdot$ R. Kawai

Medical Check-up Center, Tachikawa Medical Center,

Nagacho 2-2-16, Nagaoka, Niigata 940-0053, Japan

e-mail: ijie@venus.sannet.ne.jp and MS in men, but the relationships were not conclusive in women.

Keywords Adipose tissue disease - C-reactive protein . Diabetes $\cdot$ Metabolic syndrome $\cdot$ Vital capacity

\section{Introduction}

Metabolic syndrome (MS) or insulin resistance syndrome predicts diabetes and cardiovascular disease, but the definition and the clinical usefulness of MS are controversial [1-3]. Metabolic syndrome as a clustering of interrelated metabolic risk factors may evolve through adipose tissue disease [4] and may not only be restricted to a risk factor for diabetes and cardiovascular disease but also related to many other systemic disorders, such as chronic kidney disease (CKD) [5, 6], chronic lung disease [7], and fatty liver disease [8]. While a lower vital capacity (VC) has been reported to be a predictor of the development of insulin resistance or diabetes in Western countries [9-13], there are few reports on the relationship between respiratory function and metabolic syndrome or diabetes in the general Japanese population [14, 15]. In contrast to impaired restrictive lung function, impaired obstructive lung function is not associated with diabetes [12-16]. The underlying mechanisms of the association between a lower $\mathrm{VC}$ and diabetes are not known, but insulin resistance is thought to play a role [9-13] and, recently, blood levels of surfactant protein A (SP-A) have been reported to be associated with insulin resistance [17]. SP-A, which is a marker of interstitial lung injury, may be a possible link between lower VC and insulin resistance. We have investigated a cross-sectional association between $\mathrm{VC}$ and MS and between $\mathrm{VC}$ and diabetes in Japanese men and women. 
We adopted the revised National Cholesterol Education Program (NCEP) criteria [2] as modified for Japanese [1] for defining MS because the Japanese definition of MS (JMS) [18] requires obesity as an inevitable component of MS, and the NIPPON DATA 90 [19] has stated that this concept is not compatible with the practice of preventive medicine among Japanese.

\section{Materials and methods}

\section{Subjects}

Between 1 April and 31 October 2008, 1692 men and 987 women visited our medical check-up center to undergo optional complete medical check-ups. All visitors to the center were required to fill out a questionnaire made by Ministry of Health, Labor, and Welfare for the purpose of "Special Health Examination and Instruction". This questionnaire includes questions on cardiovascular disease status, smoking status, antihypertensive and hypoglycemic medication, and alcohol consumption. Based on the answers, a number of individuals were consecutively excluded from the study: (1) lack of signed consent (nine men, 11 women); (2) lack of respiratory function data (nine men, nine women); (3) serum levels of high-sensitivity C-reactive protein (hs-CRP) $>10 \mathrm{mg} / \mathrm{L}$ (20 men, nine women); (4) missing percentage body fat data (three men, one woman). The final study cohort consisted of 1651 men [mean age \pm standard deviation (SD) $51.5 \pm 9.2$ ] years and 957 women (mean age \pm SD $51.0 \pm 10.0$ years). The occupations ranged from teacher, civil servant, office worker, laborer, farmer, merchant, housekeeper, and retiree. All resided in Nagaoka and Kashiwazaki Cities and the neighboring agricultural district. The protocol for the study was approved by the ethics committee of the Tachikawa Medical Center, and signed informed consent was obtained from each subject.

\section{Measurements}

After an overnight fast, blood samples were obtained to measure serum levels of routine medical check-up markers: glucose, triglycerides, high-density lipoprotein cholesterol (HDLc), low-density lipoprotein cholesterol (LDLc), hemoglobin A1c, uric acid, blood cell counts, electrolytes, and liver and kidney function tests, including gamma glutamyltransferase (GGT), alanine aminotransferase (ALT), and hs-CRP. Chemical measurements were all performed at BML Nagaoka (Nagaoka, Niigata, Japan) except for hs-CRP, which was measured at BML General Laboratory (Tokyo, Japan) with nephelometry using N-latex CRP-2 (Siemens Healthcare Japan, Tokyo, Japan).
The measurement limit of hs-CRP was $0.02 \mathrm{mg} / \mathrm{L}$, and the value of hs-CRP less than the measurement limit was considered to be $0.01 \mathrm{mg} / \mathrm{L}$. Respiratory function tests, including percentage vital capacity $(\% \mathrm{VC})$ and forced expiratory volume in $1 \mathrm{~s}$ divided by forced vital capacity (FVC) (FEV1/FVC) were performed with the Autospirometer System 7 (Minato Medical Science, Osaka, Japan). Percentage body fat was measured with bioelectrical impedance analysis using TBF-210 (TANITA, Tokyo, Japan). An average blood pressure was calculated from two measurements with the subjects in a sitting position after 5 min of rest. Body weight was measured with the subjects wearing a lightweight cloth provided by our center, and the weight of the cloths was subtracted from the measured body weight. Waist circumference (WC) was measured at the level of the umbilicus. Body mass index (BMI) was calculated as weight in kilograms divided by the square of height in meters. Estimated glomerular filtration rate (eGFR) was calculated as eGFR $\left(\mathrm{mL} / \mathrm{min} / 1.73 \mathrm{~m}^{2}\right)=$ $194 \times$ creatinine $^{-1.094} \times$ age $^{-0.287}$ (men) and as $194 \times$ creatinine $^{-1.094} \times$ age $^{-0.287} \times 0.739$ in women in accordance with the Japanese Society of Nephrology.

\section{Definitions}

An individual was defined as having diabetes when the fasting glucose levels $\geq 126 \mathrm{mg} / \mathrm{dL}$ or when he/she was on hypoglycemic medication. Metabolic syndrome was defined in accordance with the revised NCEP criteria [2] as three or more of the following five components: (1) WC, in which the cut point was modified for Japanese individuals to $90 \mathrm{~cm}$ for men and $80 \mathrm{~cm}$ for women, which is in line with the recommendation of the International Diabetes Federation [1]; (2) blood pressure, a systolic blood pressure (SBP) $\geq 130 \mathrm{mmHg}$ and/or a diastolic blood pressure (DBP) $\geq 85 \mathrm{mmHg}$; (3) triglycerides, $\geq 150 \mathrm{mg} / \mathrm{dL}$; (4) HDLc, $<40 \mathrm{mg} / \mathrm{dL}$ in men and $<50 \mathrm{mg} / \mathrm{dL}$ in women; (5) fasting glucose, $\geq 100 \mathrm{mg} / \mathrm{dL}$. Subjects receiving antihypertensive agents or hypoglycemic medication were considered to have the respective component. The JMS defined by the Examination Committee for Criteria of Metabolic Syndrome [18] was also examined. The criteria of JMS is a visceral adipose tissue area $\geq 100 \mathrm{~cm}^{2}$ or a $\mathrm{WC} \geq 85$ in men, $\geq 90$ in women and two or more of the following three components: (1) blood pressure, SBP $\geq 130 \mathrm{mmHg}$ and/or DBP $\geq 85 \mathrm{mmHg}$; (2) triglycerides $\geq 150 \mathrm{mg} / \mathrm{dL}$ and/or HDLc $<40 \mathrm{mg} / \mathrm{dL}$; (3) and fasting glucose $\geq 110 \mathrm{mg} / \mathrm{dL}$.

Statistical analysis

Baseline data were compared between subjects with MS and those without MS. Stepwise multiple linear regressions using fasting glucose as a dependent variable and age, WC, 
Table 1 Baseline data in men by metabolic syndrome

\begin{tabular}{|c|c|c|c|}
\hline Baseline characteristics of male study participants & Non-MS, $n=1413$ [mean (SD)] & $\mathrm{MS}, n=238[$ mean (SD) $]$ & $p$ \\
\hline Age (years) & $51.2(9.3)$ & $53.1(8.4)$ & 0.003 \\
\hline Body mass index $\left(\mathrm{kg} / \mathrm{m}^{2}\right)$ & $22.7(2.6)$ & $26.7(3.1)$ & $<0.0001$ \\
\hline Body fat $(\%)$ & $21.1(4.5)$ & $27.2(4.6)$ & $<0.0001$ \\
\hline Waist circumference $(\mathrm{cm})$ & $82.5(7.1)$ & $94.1(6.8)$ & $<0.0001$ \\
\hline Systolic blood pressure (mmHg) & $120.1(16.5)$ & $134.1(15.6)$ & $<0.0001$ \\
\hline Diastolic blood pressure $(\mathrm{mmHg})$ & $76.5(10.2)$ & $84.2(10.2)$ & $<0.0001$ \\
\hline Fasting glucose $(\mathrm{mg} / \mathrm{dL})$ & $93.7(12.0)$ & $107.4(18.5)$ & $<0.0001$ \\
\hline Triglycerides (mg/dL) & $95(70,128)^{\mathrm{a}}$ & $171(138,228)^{\mathrm{a}}$ & $<0.0001$ \\
\hline HDL cholesterol (mg/dL) & $59.3(14.1)$ & $47.1(10.4)$ & $<0.0001$ \\
\hline High-sensitivity CRP (mg/L) & $0.27(0.15,0.53)^{\mathrm{a}}$ & $0.62(0.38,1.27)^{\mathrm{a}}$ & $<0.0001$ \\
\hline Gamma glutamyltransferase (U/L) & $33(23,52)^{\mathrm{a}}$ & $51(35,79)^{\mathrm{a}}$ & $<0.0001$ \\
\hline Alanine aminotransferase (U/L) & $21(16,28)^{\mathrm{a}}$ & $30(23,44)^{\mathrm{a}}$ & $<0.0001$ \\
\hline White blood cell count $\left(\mathrm{L}^{-6}\right)$ & $5438(1435)$ & $6242(1494)$ & $<0.0001$ \\
\hline LDL cholesterol (mg/dL) & $119.0(28.7)$ & $127.1(30.7)$ & $<0.0001$ \\
\hline Uric acid (mg/dL) & $6.1(1.3)$ & $6.6(1.4)$ & $<0.0001$ \\
\hline Hemoglobin A1c (\%) & $5.0(0.5)$ & $5.5(0.7)$ & $<0.0001$ \\
\hline Vital capacity $(\%)$ & $96.3(11.0)$ & $92.4(11.3)$ & $<0.0001$ \\
\hline FEV1/FVC (\%) & $80.5(6.0)$ & $80.3(6.0)$ & ns \\
\hline Heart rate $(/ \mathrm{min})$ & $58.3(8.8)$ & $63.2(9.5)$ & $<0.0001$ \\
\hline \multirow[t]{2}{*}{ eGFR $\left(\mathrm{mL} / \mathrm{min}\right.$ per $\left.1.73 \mathrm{~m}^{2}\right)$} & $78.6(12.7)$ & $76.0(14.0)$ & 0.004 \\
\hline & $n(\%)$ & $n(\%)$ & $p$ \\
\hline Antihypertensive medication & $222(15.7)$ & $88(37.0)$ & $<0.0001$ \\
\hline Antidiabetic medication & $35(2.5)$ & $29(12.2)$ & $<0.0001$ \\
\hline Current smoker & $467(33.0)$ & $94(39.5)$ & $<0.05$ \\
\hline Everyday drinker & $748(52.8)$ & $120(50.4)$ & ns \\
\hline JMS & $51(3.6)$ & $163(68.5)$ & $<0.0001$ \\
\hline Diabetes & $54(3.8)$ & $40(16.8)$ & $<0.0001$ \\
\hline Cardiovascular disease & $78(5.5)$ & $24(10.1)$ & $<0.01$ \\
\hline
\end{tabular}

SD, Standard deviation; MS, metabolic syndrome defined by revised NCEP definition for Japanese; HDL, High-density lipoprotein; CRP, C-reactive protein; LDL, low-density lipoprotein; FEV1/FVC, forced expiratory volume in $1 \mathrm{~s}$ divided by forced vital capacity; eGFR, estimated glomerular filtration rate $\left(\mathrm{eGFR}=194 \times\right.$ creatinine $^{-1.094} \times$ age $^{-0.287}$ in men and $194 \times$ creatinine $^{-1.094} \times$ age $^{-0.287} \times 0.739$ in women); JMS, Japanese metabolic syndrome defined by the Japanese committee

${ }^{a}$ Median (25 and 75 percentiles)

SBP, triglycerides, HDLc, hs-CRP, GGT, ALT, and \%VC as independent variables were performed. The area under the receiver operating characteristic curve (AUC) of $-\% \mathrm{VC}$, age, WC, BMI, and body fat $\%$ for diagnosing diabetes, MS, and JMS were calculated. Stepwise logistic regressions using diabetes as a dependent variable and age, WC, SBP, triglycerides, HDLc, hs-CRP, GGT, ALT, $\% \mathrm{VC}$, smoking status, and drinking status as initial independent variables and using MS and JMS as dependent variables and age, \%VC, smoking status, and drinking status as initial independent variables were performed. The BMI, body fat $\%$, and diastolic blood pressure were excluded from initial independent variables to avoid multicollinearity. Statistical analyses were conducted with
SPSS-2 (SPSS, Chicago, IL). Means were compared with two-sided $t$ tests, and ratios were compared with chi-square tests. $p$ values $<0.05$ were considered to be statistically significant.

\section{Results}

Baseline data among men are shown in Table 1 by MS or non-MS. All MS-related risk factors other than HDLc were significantly higher and HDLc was significantly lower in MS than in non-MS subjects. Heart rate was significantly higher and \%VC and eGFR were significantly lower in MS than in non-MS subjects. The frequency of JMS, diabetes, 
Table 2 Baseline data in women by metabolic syndrome

\begin{tabular}{|c|c|c|c|}
\hline Baseline characteristics of female study participants & Non-MS, $n=894[$ mean (SD)] & MS, $n=63[$ mean (SD)] & $p$ \\
\hline Age (years) & $50.6(9.5)$ & $56.7(9.6)$ & $<0.0001$ \\
\hline Body mass index $\left(\mathrm{kg} / \mathrm{m}^{2}\right)$ & $21.4(2.8)$ & $25.8(3.3)$ & $<0.0001$ \\
\hline Body fat $(\%)$ & $26.1(5.4)$ & $33.9(5.8)$ & $<0.0001$ \\
\hline Waist circumference $(\mathrm{cm})$ & $77.9(8.1)$ & $90.0(7.8)$ & $<0.0001$ \\
\hline Systolic blood pressure $(\mathrm{mmHg})$ & $110.0(15.2)$ & $131.3(20.6)$ & $<0.0001$ \\
\hline Diastolic blood pressure $(\mathrm{mmHg})$ & $68.8(9.3)$ & $81.1(12.3)$ & $<0.0001$ \\
\hline Fasting glucose $(\mathrm{mg} / \mathrm{dL})$ & $88.0(8.5)$ & $104.4(21.7)$ & $<0.0001$ \\
\hline Triglycerides (mg/dL) & $70(54,95)^{\mathrm{a}}$ & $129(90,189)^{\mathrm{a}}$ & $<0.0001$ \\
\hline HDL cholesterol (mg/dL) & $68.1(14.1)$ & $51.9(12.4)$ & $<0.0001$ \\
\hline High-sensitivity CRP (mg/L) & $0.20(0.10,0.38)^{\mathrm{a}}$ & $0.50(0.25,0.90)^{\mathrm{a}}$ & 0.0001 \\
\hline Gamma glutamyltransferase (U/L) & $17(13,23)^{\mathrm{a}}$ & $27(18,41)^{\mathrm{a}}$ & $<0.0001$ \\
\hline Alanine aminotransferase (U/L) & $15(12,19)^{\mathrm{a}}$ & $22(16,31)^{\mathrm{a}}$ & $<0.0001$ \\
\hline White blood cell count $\left(\mathrm{L}^{-6}\right)$ & $4795(1263)$ & $5379(1113)$ & $<0.001$ \\
\hline LDL cholesterol (mg/dL) & $119.6(28.3)$ & $140.9(29.2)$ & $<0.0001$ \\
\hline Uric acid (mg/dL) & $4.4(0.9)$ & $5.3(1.2)$ & $<0.0001$ \\
\hline Hemoglobin A1c (\%) & $5.0(0.3)$ & $5.5(0.8)$ & $<0.0001$ \\
\hline Vital capacity $(\%)$ & $96.1(11.4)$ & $95.6(15.0)$ & ns \\
\hline FEV1/FVC (\%) & $82.5(5.6)$ & $81.2(5.4)$ & ns \\
\hline Heart rate $(/ \min )$ & $60.0(7.9)$ & $63.1(9.6)$ & 0.004 \\
\hline \multirow[t]{2}{*}{ eGFR $\left(\mathrm{mL} / \mathrm{min} / 1.73 \mathrm{~m}^{2}\right)$} & $80.4(13.1)$ & $75.4(13.0)$ & 0.003 \\
\hline & $n(\%)$ & $n(\%)$ & $p$ \\
\hline Antihypertensive medication & $54(6.0)$ & $31(49.2)$ & $<0.0001$ \\
\hline Antidiabetic medication & $4(0.4)$ & $7(11.1)$ & $<0.0001$ \\
\hline Current smoker & $56(6.3)$ & $4(6.3)$ & ns \\
\hline Everyday drinker & $129(14.4)$ & $9(14.3)$ & ns \\
\hline JMS & $0(0)$ & $20(31.7)$ & $<0.0001$ \\
\hline Diabetes & $6(0.7)$ & $9(14.3)$ & $<0.0001$ \\
\hline Cardiovascular disease & $25(2.8)$ & $4(6.3)$ & ns \\
\hline
\end{tabular}

${ }^{\text {a }}$ Median (25 and 75 percentiles)

and cardiovascular disease were significantly higher in MS than in non-MS subjects. Basal data among women are shown in Table 2 by MS or non-MS. All MS-related risk factors other than HDLc were significantly higher and HDLc was significantly lower in MS than in non-MS subjects. Heart rate was significantly higher and eGFR was significantly lower in MS than in non-MS subjects. But, $\% \mathrm{VC}$ was not significantly different between MS and nonMS subjects. The frequency of JMS and diabetes were significantly higher in MS than in non-MS subjects. But, prevalence of cardiovascular disease was not significantly different between MS and non-MS subjects. Table 3 shows the final result of stepwise multivariable linear regression analysis using fasting glucose as a dependent variable. \% VC was independently associated with fasting glucose in men, but not in women. AUC of -\%VC, age, waist circumference, body mass index, and body fat $\%$ for diagnosing diabetes,
MS, and JMS were presented in Table 4 and ROC curves of -\%VC for diagnosing diabetes were shown in Fig. 1. The AUC of $-\%$ VC for diagnosing diabetes, MS, and JMS were $0.647,0.606$, and 0.598 , respectively (all $p<0.0001$ ) in men and $0.639(p=0.065), 0.513(p=0.732)$, and 0.668 $(p=0.01)$, respectively, in women. The AUC of age, WC, BMI, and body fat $\%$ for diagnosing diabetes were 0.668 ( $p<0.0001), 0.630(p<0.0001)$, and $0.616(p=0.0002)$, and $637(p<0.0001)$, respectively, in men and 0.663 $(p=0.03), 0.736$ ( $p=0.002), 0.767$ ( $p=0.0004)$, and 0.723 ( $p=0.003)$, respectively, in women. Table 5 shows the final result of stepwise multivariable logistic regression analysis with backward elimination method using diabetes, MS and JMS as dependent variables. Age, WC, and \% VC in men and $\mathrm{WC}$ and \% VC in women were independently associated with diabetes. Age and \% VC in men and only age in women were independently associated with MS and age 
Table 3 Stepwise linear regression using fasting glucose as a dependent variable by gender

\begin{tabular}{lrcl}
\hline Variables & \multicolumn{1}{l}{ PRC } & $95 \%$ CI of PRC & $p$ \\
\hline Men & & & \\
Constant & 60.283 & $50.713-69.853$ & $<0.0001$ \\
Waist circumference (cm) & 0.258 & $0.172-0.343$ & $<0.0001$ \\
Age (years) & 0.266 & $0.196-0.337$ & $<0.0001$ \\
GGT (U/L) & 0.024 & $0.010-0.037$ & 0.0004 \\
Vital capacity (\%) & -0.130 & -0.188 to -0.073 & $<0.0001$ \\
SBP (mmHg) & 0.083 & $0.043-0.123$ & $<0.0001$ \\
Triglycerides (mg/dL) & 0.009 & $0.000-0.018$ & 0.04 \\
Women & & & \\
Constant & 52.111 & $45.516-58.706$ & $<0.0001$ \\
SBP (mmHg) & 0.116 & $0.075-0.158$ & $<0.0001$ \\
Waist circumference (cm) & 0.193 & $0.113-0.272$ & $<0.0001$ \\
Age (year) & 0.161 & $0.093-0.229$ & $<0.0001$ \\
High-sensitivity CRP (mg/L) & 1.575 & $0.604-2.546$ & 0.002 \\
\hline
\end{tabular}

PRC, Partial regression coefficient; CI, confidence interval; GGT, gamma glutamyltransferase; SBP, systolic blood pressure

Age, waist circumference, SBP, triglycerides, HDL cholesterol, highsensitivity CRP, GGT, ALT, and \% VC are used as initial independent variables

and \% $\mathrm{VC}$ in both men and women were independently associated with JMS.

\section{Discussion}

Metabolic syndrom has been proposed as a constellation of interrelated metabolic risk factors that appear to directly promote the development of diabetes and cardiovascular disease $[1,2]$. The predominant underlying mechanisms of MS appear to be insulin resistance [20], leptin resistance [21, 22], obesity [1], inflammation [23], endothelial dysfunction [24], and autonomic dysfunction [21]. However, in 2005, the American Diabetes Association and the European Association for the Study of Diabetes jointly stated that no existing definition of MS meets the criteria of a syndrome [3], and there have been endless debates on the pros and cons of diagnosing MS for individuals [25]. Here, we considered MS as a syndrome developing through adipose tissue disease [4]. MS may not be restricted to a risk factor for diabetes and cardiovascular disease but also related to many other systemic disorders, such as CKD [5, 6], chronic lung disease [7], and fatty liver disease [8]. Diabetes is a major cause of CKD, and diabetic nephropathy has been detected by increased urinary albumin excretion (UAE); conversely, UAE is also reported to be an independent predictor of diabetes after controlling for MS and other risk factors of diabetes [26]. Likewise, restrictive lung disease is not only a result of diabetic microangiopathy [27], but a lower VC is also reported to be an independent predictor of diabetes [12, 13]. Lazarus et al. [9] found that FVC, FEV1, and maximal mid-expiratory flow rate were predictors of hyperinsulinemia and insulin resistance. Engstrom et al. [10] reported that low FVC and FEV1 predicted incident diabetes independent of adiposity. Later on, they confirmed this finding in a larger cohort of Swedish men and women and also found that the incidence of cardiovascular disease was significantly increased among subjects with low \% VC who had developed insulin resistance [11]. Ford and Mannino reported that FVC and FEV1 but not FEV1/FVC were significantly and inversely associated with the incidence of diabetes [12]. They also found that restrictive lung disease was significantly associated with the incidence of diabetes but not obstructive lung disease. Yeh et al. [13] also concluded that lower VC predicted the development of diabetes. In addition, these researchers reported that the association between respiratory function and diabetes was graded, independent of confounding factors, and stronger in individuals who had never smoked and that it appeared to be specific to $\mathrm{VC}$, since FEV1/FVC was not at all related to diabetic risk and subjects with a lower VC had many features of MS or insulin resistance at baseline.

Here, we examined a cross-sectional relationship between respiratory function and MS and between respiratory function and diabetes. The $\% \mathrm{VC}$ was independently associated with fasting glucose in men in the multiple regressions, but not in women. The AUC of $-\% \mathrm{VC}$ for diagnosing diabetes, MS, and JMS was 0.647, 0.606, and 0.598 , respectively (all $p<0.0001$ ), in men and 0.639 $(p=0.065), 0.513(p=0.732)$, and $0.668(p=0.01)$, respectively, in women. In addition, the AUC of $-\% \mathrm{VC}$ for diagnosing diabetes was comparable with those of metabolic risk factors in men, but not in women, that of $-\% \mathrm{VC}$ for diagnosing MS or JMS was significant but lower than those of other metabolic risk factors in men, that of $-\% \mathrm{VC}$ for diagnosing MS was not significant, and that of $-\% \mathrm{VC}$ for diagnosing JMS was significant but lower than those of other metabolic risk factors in women. Age, WC, and \% VC in men and $\mathrm{WC}$ and $\% \mathrm{VC}$ in women were independently associated with diabetes. Age and $\% \mathrm{VC}$ in men and only age in women were independently associated with MS, and age and \% VC in both men and women were independently associated with JMS.

Sakuta et al. [14] reported that a decrease in \%VC was associated with diabetes, hypertension, hypertriglyceridemia, high GGT levels, and cardiovascular disease in middle-aged Japanese men. However, they did not study the relationship between \%VC and MS or hs-CRP. Nakajima et al. studied the association between respiratory function and MS in comparison with hs-CRP in a Japanese 
Table 4 Area under the ROC curve of -\% vital capacity, age, waist circumference, body mass index, and body fat percentage for diagnosing diabetes, MS, and JMS by gender

\begin{tabular}{|c|c|c|c|c|c|c|}
\hline \multirow[t]{2}{*}{ Variables } & \multicolumn{3}{|l|}{ Men } & \multicolumn{3}{|c|}{ Women } \\
\hline & AUC & $95 \% \mathrm{CI}$ & $p$ & AUC & $95 \% \mathrm{CI}$ & $p$ \\
\hline \multicolumn{7}{|l|}{ Diabetes } \\
\hline -\% vital capacity & 0.647 & $0.589-0.704$ & $<0.0001$ & 0.639 & $0.507-0.770$ & 0.065 \\
\hline Age & 0.668 & $0.620-0.715$ & $<0.0001$ & 0.663 & $0.538-0.787$ & 0.03 \\
\hline Waist circumference & 0.630 & $0.571-0.689$ & $<0.0001$ & 0.736 & $0.563-0.909$ & 0.002 \\
\hline Body mass index & 0.616 & $0.554-0.678$ & 0.0002 & 0.767 & $0.610-0.925$ & 0.0004 \\
\hline Body fat $\%$ & 0.637 & $0.577-0.697$ & $<0.0001$ & 0.723 & $0.559-0.888$ & 0.003 \\
\hline \multicolumn{7}{|l|}{ MS } \\
\hline -\% vital capacity & 0.606 & $0.567-0.646$ & $<0.0001$ & 0.513 & $0.431-0.594$ & 0.7 \\
\hline Age & 0.566 & $0.529-0.604$ & 0.001 & 0.676 & $0.609-0.743$ & $<0.0001$ \\
\hline Waist circumference & 0.889 & $0.866-0.911$ & $<0.0001$ & 0.870 & $0.831-0.909$ & $<0.0001$ \\
\hline Body mass index & 0.854 & $0.828-0.880$ & $<0.0001$ & 0.862 & $0.822-0.901$ & $<0.0001$ \\
\hline Body fat $\%$ & 0.834 & $0.809-0.859$ & $<0.0001$ & 0.848 & $0.808-0.888$ & $<0.0001$ \\
\hline \multicolumn{7}{|l|}{ JMS } \\
\hline -\% vital capacity & 0.598 & $0.557-0.640$ & $<0.0001$ & 0.668 & $0.547-0.788$ & 0.01 \\
\hline Age & 0.573 & $0.534-0.612$ & 0.001 & 0.762 & $0.666-0.858$ & $<0.0001$ \\
\hline Waist circumference & 0.874 & $0.856-0.892$ & $<0.0001$ & 0.973 & $0.960-0.986$ & $<0.0001$ \\
\hline Body mass index & 0.847 & $0.822-0.871$ & $<0.0001$ & 0.948 & $0.920-0.977$ & $<0.0001$ \\
\hline Body fat $\%$ & 0.812 & $0.785-0.839$ & $<0.0001$ & 0.954 & $0.935-0.973$ & $<0.0001$ \\
\hline
\end{tabular}

ROC, Receiver operating characteristic; AUC, area under the ROC curve

Fig. 1 Receiver operating characteristic curves of $-\%$ vital capacity for diagnosing diabetes
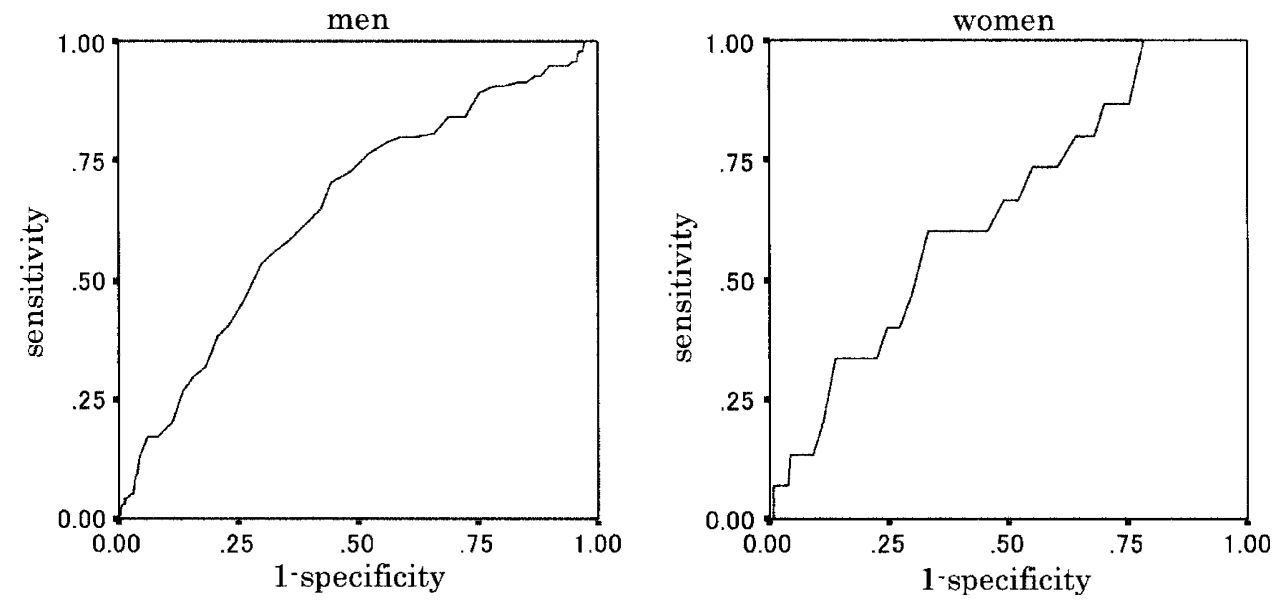

population and reported that hs-CRP and impaired restrictive pulmonary function-but not obstructive pulmonary function-were significantly associated with MS even after adjustment for WC [14]. In their report, a moderate-to-severe restrictive pattern, but not a high hsCRP level $(>3.0 \mathrm{mg} / \mathrm{L})$, was consistently associated with MS [15]. In contrast, in our study, hs-CRP is significantly associated with MS and \%VC. Their cut point of hs-CRP may be too high for a Japanese population because a reported cut point of hs-CRP as an inflammatory component of MS is $0.45 \mathrm{mg} / \mathrm{L}$ in Japanese men and $0.25 \mathrm{mg} /$ $\mathrm{L}$ in Japanese women [28]. Thus, VC was significantly associated with diabetes and MS in Japanese men, but the association was not conclusive in Japanese women. One reason for the inconclusiveness of our results in women may be that the number of subjects with diabetes in our study was too small to detect a statistical significance in women. The paradoxically positive relation between \% VC 
Table 5 Stepwise logistic regressions using diabetes, MS, and JMS as dependent variables by gender

\begin{tabular}{|c|c|c|c|c|c|c|}
\hline \multirow[t]{2}{*}{ Variables } & \multicolumn{3}{|l|}{ Men } & \multicolumn{3}{|c|}{ Women } \\
\hline & OR & $95 \% \mathrm{CI}$ & $p$ & OR & $95 \% \mathrm{CI}$ & $p$ \\
\hline \multicolumn{7}{|l|}{ Diabetes $^{\mathrm{a}}$} \\
\hline Age (year) & 1.061 & $1.037-1.087$ & $<0.0001$ & & & \\
\hline Waist circumference $(\mathrm{cm})$ & 1.051 & $1.026-1.076$ & $<0.0001$ & 1.122 & $1.065-1.181$ & $<0.0001$ \\
\hline Vital capacity $(\%)$ & 0.961 & $0.943-0.980$ & $<0.0001$ & 0.950 & $0.907-0.994$ & $<0.05$ \\
\hline \multicolumn{7}{|l|}{$\mathrm{MS}^{\mathrm{b}}$} \\
\hline Age (year) & 1.025 & $1.009-1.041$ & $<0.01$ & 1.067 & $1.040-1.096$ & $<0.0001$ \\
\hline Vital capacity $(\%)$ & 0.968 & $0.956-0.981$ & $<0.0001$ & 0.994 & $0.973-1.015$ & ns \\
\hline \multicolumn{7}{|l|}{$\mathrm{JMS}^{\mathrm{b}}$} \\
\hline Age (year) & 1.026 & $1.010-1.042$ & $<0.01$ & 1.091 & $1.045-1.140$ & $<0.0001$ \\
\hline Vital capacity $(\%)$ & 0.971 & $0.958-0.984$ & $<0.0001$ & 0.951 & $0.917-0.987$ & $<0.01$ \\
\hline
\end{tabular}

OR, Odds ratio

a Age, waist circumference, systolic blood pressure, triglycerides, HDL cholesterol, high-sensitivity CRP, GGT, ALT, \% vital capacity, smoking status, and drinking status were used as initial independent variables

b Age, \% vital capacity, smoking status, and drinking status were used as initial independent variables

and anthropometric parameters of obesity in women may result from the leanness-rather than obesity-of Japanese women. However, it is possible that there may be some gender difference in the association between $\mathrm{VC}$ and MS. The reason why low VC predicts diabetes is not known. One possible mechanism is hypoxia-induced insulin resistance [29]. However, the mild decrease in VC observed in our study and the above mentioned previous studies may not be associated with significant hypoxia. Rather, decreased muscle strength may be the link between impaired respiratory function and insulin resistance $[9,16]$. Respiratory function is partially determined by skeletal muscle strength, and low levels of hand-grip strength have predicted higher levels of fasting insulin [30]. Another possible mechanism may involve SP-A. Levels of SP-A in the blood have been reported to be associated with insulin resistance [17] and may possibly be associated with a lower VC because SP-A is a marker of interstitial lung injury.

Conclusions and limitations

Lower VC is an independent marker of diabetes and associated with MS in Japanese men. However, our study was a cross-sectional study, and the subjects were not a general population but visitors to our medical check-up center, which is in a central city of a rural region in Japan. Therefore, it is unknown whether low VC precedes the development of diabetes or not among Japanese. Further studies that include a larger number of female diabetic subjects and longitudinal ones are warranted to establish lower VC as a risk factor of diabetes in the Japanese general population.
Acknowledgments We thank all subjects who participated in the study, the staff at our Medical Check-up Center who assisted the study, Dr. Shinzo Tachikawa, Dr. Shinpei Yoshii, and Dr. Masaaki Okabe at Tachikawa Medical Center, and Professor Yoshifusa Aizawa at Niigata University Graduate School of Medical and Dental Sciences for their efforts in designing the study environment.

Conflict of interest statement We received no financial support and have no conflict of interest to disclose.

\section{References}

1. Alverti KGMM, Zimmet P, Shaw J. Metabolic syndrome: a new world-wide definition. A consensus statement from the International Diabetes Federation. Diabet Med. 2006;23:469-80.

2. Grundy SM, Cleeman JI, Daniels SR, Donato KA, Eckel RH, Franklin BA, et al. Diagnosis and management of the metabolic syndrome: a statement for health care professionals: an American Heart Association/National Heart, Lung, and Blood Institute Scientific Statement. Circulation. 2005;112:2735-52.

3. Kahn R, Buse J, Ferrannini E, Stern M. The metabolic syndrome: time for a critical appraisal: joint statement from the American Diabetes Association and the European Association for the Study of Diabetes. Diabetes Care. 2005;28:2289-304.

4. Oda E. The metabolic syndrome as a concept of adipose tissue disease. Hypertens Res. 2008;31:1285-93.

5. Tozawa M, Iseki C, Tokashiki K, Chinen S, Kohagura K, Kinjo $\mathrm{K}$, et al. Metabolic syndrome and risk of developing chronic kidney disease in Japanese adults. Hypertens Res. 2007;30:93743.

6. Kawamoto R, Kohara K, Tabara Y, Miki T. An association between metabolic syndrome and the estimated glomerular filtration rate. Intern Med. 2008;47:1399-406.

7. Fabbri LM, Rabe KF. From COPD to chronic systemic inflammatory syndrome? Lancet. 2007;370:797-9.

8. Kotronen A, Yki-Jarvinen H. Fatty liver: a novel component of the metabolic syndrome. Arterioscler Thrommb Vasc Biol. 2008;28:27-38. 
9. Lazarus R, Sparrow D, Weiss ST. Baseline ventilator function predicts the development of higher levels of fasting insulin and fasting insulin resistance index: the Normative Aging Study. Eur Respir J. 1998;12:641-5.

10. Engstrom G, Janzon L. Risk of developing diabetes is inversely related to lung function: a population-based cohort study. Diabet Med. 2002;19:167-70.

11. Engstrom G, Hedblad B, Nilsson P, Wollmer P, Berglund G, Janzon L. Lung function, insulin resistance and incidence of cardiovascular disease: a longitudinal cohort study. J Intern Med. 2003;253:574-81.

12. Ford ES, Mannino DM. Prospective association between lung function and the incidence of diabetes. Findings from the National Health and Nutrition Examination Survey Epidemiologic Follow-up Study. Diabetes Care. 2004;27:2966-70.

13. Yeh H, Punjabi NM, Wang N, Pankow JS, Duncan BB, Brancati FL. Vital capacity as a predictor of incident type 2 diabetes. The Atherosclerosis Risk in Communities Study. Diabetes Care. 2005;28:1472-9.

14. Sakuta H, Suzuki T, Yasuda H, Ito T. Vital capacity and selected metabolic diseases in middle-aged Japanese men. Can Respir J. 2006;13:79-82.

15. Nakajima K, Kubouchi Y, Muneyuki T, Ebata M, Eguchi S, Munakata H. A possible association between suspected restrictive patter as assessed by ordinary pulmonary function test and the metabolic syndrome. Chest. 2008;134:712-8.

16. Fimognari FL, Pasqualetti P, Moro L, Franco A, Piccirillo G, Pastorelli R, et al. The association between metabolic syndrome and restrictive ventilatory dysfunction in older persons. J Gerontol. 2007;62:760-5.

17. Fernandez-Real JM, Chico B, Shiratori M, Nara Y, Takahashi H, Ricart W. Circulating surfactant protein A (SP-A), a marker of lung injury, is associated with insulin resistance. Diabetes Care. 2008;31:958-63.

18. The Examination Committee for Criteria of Metabolic Syndrome. Definition and criteria of metabolic syndrome (in Japanese). J Jpn Soc Intern Med. 2005;94:794-809.

19. Kadota A, Hozawa A, Okamura T, Kadowaki T, Nakamura K, Murakami Y, et al. Relationship between metabolic risk factor clustering and cardiovascular mortality stratified by high blood glucose and obesity: NIPPON DATA 90, 1999-2000. Diabetes Care. 2007;30:1533-8.
20. Reaven GM. Role of insulin resistance in human disease. Diabetes. 1988;37:1595-607.

21. Katagiri H, Yamada T, Oka Y. Adiposity and cardiovascular disorders: disturbance of the regulatory system consisting of humoral and neuronal signals. Circ Res. 2007;101:27-39.

22. Cnop M, Landchild MJ, Vidal J, Havel PJ, Knowles NG, Carr $\mathrm{DR}$, et al. The concurrent accumulation of intra-abdominal and subcutaneous fat explains the association between insulin resistance and plasma leptin concentrations: distinct metabolic effects of two fat compartments. Diabetes. 2002;51:1005-15.

23. Dandona P, Aljada A, Chaudhuri A, Mohanty P, Garg R. Metabolic syndrome: a comprehensive perspective based on interactions between obesity, diabetes, and inflammation. Circulation. 2005; 111:1448-54.

24. Kim J, Montagnani M, Koh KK, Quon MJ. Reciprocal relationships between insulin resistance and endothelial dysfunction. Molecular and pathophysiological mechanisms. Circulation. 2006;113:1888-904.

25. Sattar N, McConnachie A, Shaper G, Blauw G, Buckley BM, de Craen AJ, et al. Can metabolic syndrome usefully predict cardiovascular disease and diabetes? Outcome data from two prospective studies. Lancet. 2008;371:1927-35.

26. Brantsma AH, Bakker SJL, Hillege HL, de Zeeuw D, de Jong PE, Gansevoort RT, and the PREVEND Study Group. Urinary albumin excretion and its relation with $\mathrm{C}$-reactive protein and metabolic syndrome in the prediction of type 2 diabetes. Diabetes Care. 2005;28:2525-30.

27. Chance WW, Rhee C, Yilmaz C, Dane DM, Pruneda ML, Raskin $\mathrm{P}$, et al. Diminished alveolar microvascular reserves in type 2 diabetes reflect systemic microangiopathy. Diabetes Care. 2008;31:1596-601.

28. Oda E, Kawai R. A tentative cut point of high-sensitivity $\mathrm{C}$-reactive protein for a component of metabolic syndrome in Japanese. Circ J. 2009;73:755-9.

29. Regazzetti C, Peraldi P, Gremeaux T, Najem-Lendom R, BenSahra I, Cormont M, et al. Hypoxia decreases insulin signaling pathways in adipocytes. Diabetes. 2009;58:95-103.

30. Lazarus R, Sparrow D, Weiss ST. Hand-grip strength and insulin levels: cross-sectional and prospective associations in the Normative Aging Study. Metabolism. 1997;46:1266-9. 